\title{
Rückblick
}

\section{und Dank}

Die Programmatik eines Buchs zu relationalen Praktiken beginnt sich wahrscheinlich erst einzulösen, wenn das Buch auch gelesen wird. Vorab nehmen wir das Ende seiner Produktion zum Anlass, um uns als Herausgeber_innen zu den Bedingungen unserer Kollaboration in Beziehung zu setzen und deren Verflechtung mit den Arbeitskontexten anderer zu reflektieren. Abschließend wollen wir sichtbar machen, wer und auch was seit Beginn der Tagungskonzeption 2017 bis zur pandemiebedingt verspäteten Drucklegung 2021 unsere Forschungsarbeit ermöglicht hat.

An erster Stelle möchten wir all denen herzlich danken, die zur Tagung sowie zu diesem Band beigetragen haben. Ihre Vorträge, Lecture Performances und Einreichungen waren Grund, Dreh- und Angelpunkt unserer Zusammenarbeit. Vom detaillierten Dialog mit den Autor_innen über die inhaltliche Ausrichtung und Gestaltung ihrer Texte haben wir als Redakteur_innen, Forschende und Lernende gleichermaßen profitiert.

Institutionell an der Universität der Künste Berlin beheimatet und gefördert von der Deutschen Forschungsgemeinschaft, war das Graduiertenkolleg „Das Wissen der Künste“ unser Arbeits- und Diskussionskontext. Mit konstruktiver Kritik und ebenso viel Vertrauen hat uns das Leitungsteam des Kollegs bei unserem Vorgehen unterstützt. Namentlich danken möchten wir dafür Barbara Gronau, Kathrin Busch und Stefan Neuner sowie ganz besonders Kathrin Peters, die uns als "teilnehmende Beraterin“ mit ihrer Erfahrung und Expertise zur Seite stand. Ein großer Dank gilt zudem unseren Kolleg_innen und Mit-(Post-)Doktorand_innen, die durch ihre Rückfragen und Anregungen zu unseren Konzepten entscheidend beigetragen haben. Die Tagung aktiv mitgestaltet haben im Juli 2018: Juana Awad, Julian Bauer, Georg Dickmann, Lisa Großmann, Elsa Guily, Grit Köppen, Sebastian Köthe, Wilma Lukatsch, Robert Patz, Irina Raskin und Renate Wöhrer.

Neben dem Fach- und Praxiswissen akademischer Forschung braucht es auch jene, die an der Schnittstelle dieser Bereiche arbeiten und Ressourcen verfügbar machen. Kenntnisreich, sowohl was Verwaltung und Management als auch die besonderen Bedürfnisse des Tagens und Publizierens in den Künsten und mit Künstler_innen angeht, setzten sich 
unsere wissenschaftlichen Koordinatorinnen Juana Awad und Christina Deloglu-Kahlert für unser Vorhaben ein. Unterstützt haben sie dabei die Forschungsstudentinnen Johanna Heyne, Alicja Schindler, Sarah Hampel und Xin Wang.

Da wir unsere individuellen Forschungsprojekte während der Arbeit an diesem Buch in verschiedenen Städten verfolgten, wurde der Ort dieses Publikationsprojekts zu einem zunehmend virtuellen. Zeitversetzt wie gemeinsam daran zu arbeiten, wurde durch die Nutzung verschiedener Infrastrukturen (etwa von Messenger-Diensten, browserbasierter Textverarbeitungssoftware, Serverspeicherplatz) möglich. Mangels hinreichend zuverlässiger Infrastrukturen an der Universität nutzten wir dafür kommerzielle Anbieter. Selbstkritisch sehen wir hier noch Verbesserungsbedarf und möchten auf einen offenen Brief des Constant-Kollektivs mit einer Liste alternativer Dienste hinweisen: pad.constantvzw. org/p/elephant

Sich zwischen wechselnden Arbeitsorten bewegen zu können, ist zugleich ein Privileg, das wir als Mitglieder einer temporären Forschungsgruppe auch all jenen verdanken, die eine Universität verwalten, pflegen und mit Leben füllen. Besonders durften wir das während unserer Tagung im Medienhaus der Universität der Künste Berlin erfahren.

Nicht nur dort, auch noch im Zuge der Arbeit an diesem Buch konkretisierte sich die abstrakte Ausgangsfrage How to relate? in immer kleinteiligeren Fragen. Einen bedeutenden Beitrag dazu leistete das Lektorat, das Ulf Heidel für den deutsch- und Michael Taylor für den englischsprachigen Teil verantworteten. Für ihre engagierten Vorschläge, Rückfragen an die Texte und ihre Geduld mit diesem zweisprachigen Buch danken wir beiden.

Ebenso epistemischen Anteil an dieser Publikation hat deren „gestaltete Lesbarkeit“ durch Jenny Baese. In Form von Plakaten und dieser Publikation hat sie unseren Tagungs- und Publikationskonzepten zu Visualität wie Materialität verholfen.

Die Herausgeber_innen 
Einführung zum Vortrag von Nora Sternfeld auf der Tagung How to Relate: Aneignen, Vermitteln, Figurieren, 05.-07.07.2018 an der Universität der Künste Berlin 
